\title{
A EXPLORAÇÃO DOS ICEBERGS À LUZ DO TRATADO DA ANTÁRTIDA
}

\author{
Reinaldo Caixeta Machado ${ }^{1}$ \\ André de Paiva Toledo
}

\begin{abstract}
RESUMO: A população mundial vem travando uma luta contra a escassez de água. Sabe-se que grande parte das reservas de água doce estão localizadas nos polos. Praticamente toda a extensão da Antártida é envolvida por um manto de gelo. Enormes blocos de gelo se desprendem do maciço, sendo lançados à deriva no mar. A princípio, esses recursos podem ser explorados e aproveitados. Porém, o Território Antártico está submetido ao Protocolo de Proteção Ambiental do Tratado da Antártida, que veda qualquer atividade minerária. É necessário verificar a natureza jurídica dos icebergs para então atestar a sua legitimidade de exploração.
\end{abstract}

Palavras-chave: Antártida; Icebergs; Água Doce; Tratado da Antártida.

\section{THE EXPLORATION OF ICEBERGS AT THE LIGHT OF THE ANTARCTIC TREATY}

\begin{abstract}
The world population has been fighting a fight against water scarcity. Most of the freshwater reserves are known to be located at the poles. Virtually the entire length of Antarctica is surrounded by a blanket of ice. Huge blocks of ice come off the massif, drifting into the sea. At first these resources can be exploited and harnessed. However, the Antarctic Territory is subject to the Antarctic Treaty Environmental Protection Protocol, which bans any mining activity. It is necessary to verify the legal nature of icebergs in order to attest to their legitimacy of exploitation.
\end{abstract}

Keywords: Antarctica; Icebergs; Drinkable Water; Antarctic Treaty.

\footnotetext{
${ }^{1}$ Mestrando em Direito Ambiental e Desenvolvimento Sustentável pela Escola Superior Dom Helder Câmara. Especialização em Direito Ambiental e Urbanístico pela Universidade Anhanguera (2010). Especialista en Derecho Ambiental frente al Câmbio Climático y Agotamiento de los Recursos Naturales (Universidad Castilha La-Mancha - Toledo 2019, Espanha). Possui Bacharelado em Direito pelo Centro Universitário do Triângulo (2002). É ssecretário do Grupo de Pesquisa Licenciamento Ambiental e Avaliação de Impacto da Escola Superior Dom Helder Câmara. Aadvogado e membro da Comissão de Direito Ambiental da OAB $65^{\text {a }}$ Subseção de Patrocínio. Faz parte integrante do quadro societário na empresa Agrosolos Agronomia e Meio Ambiente Ltda, onde atua como Coordenador de Projetos Ambientais. Desde 2014 é professor universitário do UNICERP Campus Patrocínio, onde leciona as disciplinas de Direito Ambiental, Direito Urbanístico, Direito Agrário e Direito e Cidadania (Curso Direito). Currículo Lattes: < http://lattes.cnpq.br/9914684229383846>. Endereço eletrônico: reinaldo@agrosolos.com.br.

2 Doutor em Direito pela Université Panthéon-Assas Paris II (Sorbonne). Mestre e Bacharel em Direito pela Universidade Federal de Minas Gerais (UFMG). Professor do Programa de Pós-Graduação em Direito da Escola Superior Dom Helder Câmara. Coordenador do Grupo de Estudos em Direito Internacional Público (GEDIP) e do Grupo de Estudos em Direito do Mar (GEDIMAR), ambos do Centro de Simulação e Intercâmbio (CSI) da Escola Superior Dom Helder Câmara. Diretor do Instituto Brasileiro de Direito do Mar (IBDMAR). Membro Associado do Institut de Recherche en Droit International et Européen de la Sorbonne (IREDIES). Membro da Société Française pour le Droit International (SFDI). Advogado (OAB/MG 98.452). Tabelião do $1^{\circ}$ Ofício de Notas de Campos Altos - MG. Currículo Lattes: < http://lattes.cnpq.br/3188685307485637 > Endereço eletrônico: depaivatoledo@gmail.com
} 


\section{Introdução}

O notório crescimento da população, assim como os novos padrões de consumo, precisa decididamente ser enfrentado e superado neste século XXI. Duas correntes que apresentam inegável relevância no cenário internacional fazem parte desse desafio transfronteiriço: o aumento crescente da população mundial, com o incremento da demanda por água em contraponto à sua escassez.

A água doce utilizada nas demandas antrópicas é proveniente de represas, rios, lagos, açudes, reservas subterrâneas e, em certos casos, do mar, depois do processo de dessalinização. O problema global da crescente escassez de água potável se deve à dependência que todas as atividades econômicas têm desse recurso vital, além dos fatores relacionados ao clima, alterado pelo próprio homem, como acredita boa parte da comunidade científica.

A depreciação qualitativa e quantitativa das fontes de água superficiais e subterrâneas tem causado inúmeros impactos nos recursos hídricos, principalmente pelo lançamento inadequado de resíduos sólidos, rejeitos industriais e efluentes sanitários não tratados. Ao longo das últimas décadas, isso tem provocado um aumento drástico das consequências negativas suportadas pelo meio ambiente e pelo próprio ser humano nele inserido, dando origem a uma infinidade de doenças.

Não obstante, à falta de disponibilidade e ao consumo indiscriminado de água soma-se a externalidade da má distribuição, fazendo com que a água chegue desigualmente a boa parte da comunidade do planeta, que carece de abastecimento seguro e de saneamento básico.

Apesar de ser necessária uma otimização do uso dos recursos hídricos, ela não se mostra como única medida a ser implementada. Os estudos de novas alternativas voltadas para o suprimento de água doce e viáveis do ponto de vista ambiental e econômico têm inigualável relevância e devem contar com um debate profundo através da mobilização e da criação de uma governança internacional direcionada para este problema comum.

Como se sabe, grande parte das reservas de água doce do mundo está localizada nos polos, especialmente no continente Antártico, na forma de icebergs. O debate sobre a possibilidade de exploração e utilização da água doce vinda dos icebergs não é recente e nem 
absurda. Nas últimas décadas, foram criadas várias discussões técnicas e jurídicas em torno dessa solução para a escassez de água.

O fato é que, através de acordos multilaterais firmados entre vários países, houve verdadeira internacionalização do espaço Antártico, inclusive com a suspensão das reivindicações de soberania sobre o território austral. Obviamente, não se trata de renúncia à soberania, mas somente um alívio para as tensões internacionais que envolvem a Antártida e seus potenciais.

De acordo com o Tratado da Antártica e do Protocolo ao Tratado da Antártica sobre a Proteção ao Meio Ambiente (Protocolo de Madrid), assinado em 4 de Outubro de 1991 e entrando em vigor em 14 de Janeiro de 1998, não poderá ser exercida nenhuma atividade de exploração com fins econômicos no continente até o ano de 2048, sendo permitida somente a realização de estudos científicos.

O território da Antártida tem histórico de disputas pelo enorme potencial de exploração dos seus recursos naturais, muitos deles ainda sequer estimados. O Tratado da Antártida não colocou um fim nessas disputas. Além do interesse econômico por parte da comunidade internacional, outros elementos importantes impulsionaram as animosidades entre Estados e terão, seguramente, reflexos tanto políticos quanto relacionados à segurança nos próximos anos.

A própria amplitude do que vem a ser a pesquisa científica nos remete a uma crítica relacionada ao fato de tais intervenções ultrapassarem a sua real finalidade. Citamos aqui, como exemplo, os impactos gerados pelo Japão com a caça às baleias, que se respalda nos fins de "estudos".

Nesta esteira, surge instigante debate com alicerce na necessidade de classificar os icebergs do continente Antártico. Este artigo teve como problema de pesquisa o seguinte questionamento: há legitimação ou ilicitude na exploração de icebergs dentro do contexto jurídico internacional atual tendo em vista os impedimentos trazidos pelo Tratado da Antártida? Isto porque o referido protocolo não trata de forma clara da natureza jurídica dos icebergs, ou seja, se possuem as mesmas limitações de exploração e uso que os recursos minerais.

Assim, dentre os objetivos do artigo está o de traçar um painel sobre o tema através de análises e pesquisas na literatura especializada com o apoio das áreas de engenharia de minas 
e de geologia. A intenção é desmistificar a definição de bens minerais vez que a análise puramente jurídica se mostra insuficiente para o esclarecimento da questão.

Como metodologia, foi utilizada a pesquisa qualitativa, exploratória e descritiva. $\mathrm{O}$ método empregado foi o hipotético-dedutivo. Quanto à técnica de pesquisa, foi utilizada a pesquisa bibliográfica e documental para coleta dos dados apresentados, na tentativa de identificar as nuances e particularidades da Antártica, dentre outros temas relevantes para a questão da exploração dos icebergs. Já em relação aos instrumentos de coleta de dados, foi utilizado o observador não participante.

Em sua maioria, os trabalhos consultados estão em português. Porém, optou-se por manter o idioma original nas citações de bibliografias estrangeiras.

\section{OS ICEBERGS}

Os processos que levam à erosão glacial ocorrem sob as massas de gelo, o que gera enorme dificuldade de observação por parte da comunidade científica. Por esse motivo, muitos estudos ainda são inconclusivos.

O efeito que atinge as geleiras é chamado de desagregação (calving). Devido a ele, partes se soltam do bloco continental como consequência de fratura interna intensa pelo contato com o mar e pela exposição direta à força das marés (ROCHA-CAMPOS, 2000, p. 218).

Os icebergs são verdadeiras montanhas geladas formadas por esses processos erosivos e lançadas no oceano. A partir daí, os icebergs flutuam à deriva, podendo apresentar tamanhos e formatos variados, dentre eles, o tabular ${ }^{3}$.

Estimativas demonstram que o manto de gelo da Antártida totaliza cerca de 14 milhões de quilômetros quadrados, podendo alcançar incríveis 4.000 metros de espessura. 91\% desse manto é constituído por água doce, o que representa cerca de $75 \%$ do total da água doce encontrada no globo (ROCHA-CAMPOS, 2000, p. 218).

Ainda que, em primeira análise, os icebergs apresentem um aspecto estático, estão em constante movimento, isto é, nem sempre se encontram conectados à plataforma continental. Logo, esta capacidade dos mesmos de se deslocarem por longas rotas em alto mar resulta em

\footnotetext{
${ }^{3}$ Os icebergs com formatos tabulares são placas de gelo flutuantes e mais comuns na Antártida. Muitos deles possuem dimensões maiores que cidades e, até mesmo, estados brasileiros.
} 
implicações jurídicas próprias quanto ao eventual exercício da soberania dos Estados no que diz respeito à sua exploração, conforme será tratado adiante.

\section{NATUREZA JURÍDICA DOS ICEBERGS: RECURSO MINERAL OU NÃO MINERAL?}

Recurso natural pode ser definido como qualquer elemento ou aspecto da natureza que esteja sob demanda, seja passível de uso ou esteja sendo usado direta ou indiretamente pelo Homem na satisfação de suas necessidades físicas e culturais em determinado tempo e espaço.

Os recursos naturais são componentes da paisagem geográfica, sendo materiais ou não. Ainda não sofreram importantes transformações pela ação antrópica e sua gênese independe do homem. A eles foram atribuídos, historicamente, valores econômicos, sociais e culturais. De qualquer forma, sempre haverá alguma alteração no ambiente, seja quando da exploração, apropriação ou do uso dos recursos naturais. Tais alterações podem ter impacto negativo se a apropriação dos recursos desconsiderar as dinâmicas naturais e/ou orientar-se por procedimentos não éticos. Além da demanda, da ocorrência e dos meios técnicos, a apropriação e o uso dos recursos naturais podem depender, também, de questões geopolíticas, sobretudo quando se caracterizam como estratégicos, envolvendo disputas entre povos. Se, por um lado, as dinâmicas naturais explicam a riqueza de recursos naturais de algumas nações, as dinâmicas sociais podem explicar a não correspondência direta entre disponibilidade de recursos naturais e bem estar e desenvolvimento humano (VENTURI, 2006).

Venturi também diz em seu trabalho que os recursos naturais incluem matérias-primas industriais e recursos renováveis, como a madeira e a pesca, mas também outros recursos ambientais comuns, como água doce limpa, que são usados ou apoiam todas as atividades econômicas existentes.

Quando se trata da exploração de recursos, a definição de "recurso mineral" precisa ser abordada. $\mathrm{O}$ conceito se baseia nos minerais de maior viabilidade econômica e é definido como uma concentração ou ocorrência de material natural, sólido e de interesse econômico na superfície ou subsuperfície da crosta terrestre onde forma, teor ou qualidade e quantidade justifiquem a extração econômica. Vão desde elementos mais simples (pedras e materiais de construção) até os mais complexos (ferro, ouro e prata). 
Segundo a definição apresentada, as porções de um depósito mineral que não têm perspectivas razoáveis de extração econômica não podem ser incluídas como sendo recursos minerais.

Já a US Geology Survey considera que o conceito de recurso mineral deve ser descrito como sendo a concentração de substâncias sólidas, líquidas ou gasosas que ocorrem naturalmente dentro ou sobre a crosta terrestre, de forma a que a extração de certo material seja atualmente ou potencialmente viável. O material classificado como reserva é aquela parte de uma fonte produtiva com lucro no momento da classificação. Assim, segundo essa definição, o recurso mineral agrega valor econômico ou pode vir a ter potencial econômico. (SURVEY, 1973).

Quando o mineral ou a rocha apresenta importância econômica, o termo utilizado é modificado, passando a ser "minério". Assim, minério é o mineral que pode ser aproveitado economicamente pelo homem (SERRA, 2009). As jazidas são formadas por esse material.

Diante dos conceitos preliminares apresentados, cabe a seguinte indagação: são os icebergs recursos naturais equiparados a quaisquer outros recursos minerais? Isso porque, conforme visto alhures, os icebergs são criados pelo desprendimento de placas das plataformas continentais que levaram milhares de anos para serem formadas. Assim, é necessário verificar se devem possuir natureza jurídica própria. Tomaremos emprestado conceitos técnicos com o intuito de apresentar uma resposta mais adequada.

Chama a atenção, dentre as definições do termo "mineral" acima mencionadas, a cristalização e a caracterização dos minerais como sendo sólidos. De fato, Teixeira et al. (2000) frisam que esses compostos não são líquidos e nem gases. São cristalinos uma vez que os átomos que os constituem estão dispostos em arranjo tridimensional ordenado. Cada um deles tem sua estrutura individualizada, não havendo, assim, a mesma disposição atômica em diferentes minerais.

Press et al. (2006) especifica que o único líquido considerado como espécie mineral é o mercúrio. Completa afirmando que o gelo formado naturalmente nas calotas polares é exemplo de mineral, mas a água líquida, por sua vez, tendo em vista seu estado físico, não é.

A utilização econômica fez com que a água passasse a ser reconhecida como um recurso hídrico, semelhante aos recursos minerais quando utilizados economicamente. Por outro lado, a escassez de água está fazendo com que se torne não mais um bem abundante e 
disponível para todos, mas um recurso finito ao qual é atribuído valor econômico e cuja utilização deve ser objeto de pagamento por seus usuários.

Por tudo isso, vale ressaltar que, atualmente, a água está sendo apontada como um recurso natural de altíssimo valor econômico, estratégico e social, haja vista que todos os setores de atividade humana necessitam fazer uso dela para desempenhar suas funções. Portanto, embora a água seja um recurso natural renovável, o que se espera a partir de agora é que haja uma corrida contra o tempo visando a um uso racional, tratando-se a água com muito cuidado, evitando-se gastos excessivos e indiscriminados, e a poluição dos mananciais. (TEIXEIRA, 2000).

Logo, a classificação dos icebergs como recurso mineral de alto valor econômico e com potencial de exploração mostra-se como sendo satisfatória.

No entanto, merece alerta o fato de que os icebergs não possuem regime específico de classificação. A apropriação, a exploração e a utilização como fonte de água doce são atualmente regidas por outros regimes legais aplicáveis por omissão ou por analogia e que fornecem respostas diretas ou indiretas à sua classificação.

\section{O TRATADO DA ANTÁRTIDA E A PROTEÇÃO AMBIENTAL}

Há na Antártica reservas conhecidas de petróleo e de carvão, bem como depósitos minerais, embora esses estoques não sejam conhecidos em detalhe. Nos últimos 50 anos de pesquisa científica, não foram encontrados grandes depósitos de rochas mineralizadas. A mineração na Antártida seria muito difícil, perigosa e cara já que o clima é severo, o gelo é muito denso e o continente é muito distante dos principais centros populacionais. Isso tornaria o transporte de minerais e equipamentos dentro e fora da Antártica um manejo bem complexo. A perfuração também seria difícil devido às enormes quantidades de gelo em movimento, aos icebergs e à enorme profundidade (4 a $5 \mathrm{~km}$ de espessura), economicamente inviável.

O maior recurso natural encontrado na Antártida é a água potável, na forma de seu imenso manto de gelo (22,5 milhões de $\mathrm{km}^{3}$ de água). Estudos para avaliar o aproveitamento comercial do gelo antártico por meio do transporte de icebergs para costas áridas do planeta foram realizados no início da década de 80 . Naquela oportunidade, ficou clara a inviabilidade econômica da extração do gelo antártico com base na tecnologia existente. No entanto, a 
crescente escassez desse recurso deve manter vivo o interesse no assunto nas próximas décadas.

No caso da exploração e do uso da água doce dos icebergs da Antártida, Pinto entende que "no se trata sólo de explotar un recurso que abunda especialmente en la Antártica, sino que de saber cuál es el marco jurídico bajo el que dicha explotación eventualmente puede llevarse a cabo" (PINTO, 2016, p. 2).

Como fenômenos eminentemente ligados às relações internacionais, o Tratado da Antártida e o Protocolo da Antártida sobre a Proteção ao Meio Ambiente (Protocolo de Madrid), juntamente com outras convenções de igual importância para a gestão dos recursos naturais naquele continente, formam o que se denomina Sistema do Tratado da Antártida (STA).

A mineração comercial na Antártida sempre foi repelida graças ao Sistema do Tratado da Antártida que baniu, pelo menos em tese, a exploração para fins exclusivamente econômicos sob o Protocolo Ambiental. Quando o tratado original foi assinado em 1959, a temática minerária não foi incorporada e discutida formalmente. Necessário dizer que a questão da mineração foi aventada pela primeira vez em 1970 pelo Reino Unido e pela Nova Zelândia diante de provocações de empresas de mineração interessadas em explorar o Oceano Antártico.

Entre 1982 e 1988, um conjunto de duras medidas para proteção ambiental foi estabelecido pela Convenção sobre a Regulamentação das Atividades de Recursos Minerais Antárticos (CRAMRA). Segundo a Convenção, a mineração poderia acontecer caso todas as partes concordassem que não haveria riscos para o meio ambiente. O objetivo da Convenção era ter um marco para o avanço de qualquer mineração futura. Em 1989, a França e a Austrália se recusaram a assinar a Convenção, defendendo que nenhuma mineração deveria ser permitida na Antártida. A CRAMRA nunca entrou em vigor, mas ajudou a fornecer a estrutura para o Protocolo de Proteção Ambiental. Este sim entrou em vigor em 1998.

O Protocolo de Madrid, também conhecido como "Proteção ao Meio Ambiente", foi incorporado ao Tratado da Antártida. As disposições do referido tratado foram aplicadas à área situada ao sul de 60 graus de latitude sul, inclusive às plataformas de gelo. Porém, nada em contrário capaz de alterar os direitos ou o exercício dos direitos de qualquer Estado soberano foi decretado, de acordo com o direito internacional aplicável ao alto-mar, dentro daquela área (artigo VI, Tratado Antártida). 
A estipulação do critério objetivo de referência geográfica nos parece suficiente para evitar qualquer confusão no que tange à aplicação das limitações criadas pelo Tratado da Antártida em alto-mar, o que certamente impacta a pesquisa sobre a possibilidade de exploração dos icebergs já deslocados da plataforma continental.

Neste sentido, Pinto (2016), citando Joyce (1991), diz que a característica de mobilidade dos icebergs impõe a necessidade de uma análise mais aprofundada quanto ao fato desse recurso pertencer a qualquer Estado quando estiver em águas submetidas ao regime do alto-mar, ou se os icebergs pertenceriam ao Estado de onde se originou.

A questão se mostra ainda controvertida, tendo em vista que parte da doutrina entende que, mesmo no caso de os icebergs estarem em zona econômica exclusiva (ZEE), a questão jurídica não resolvida persistiria, podendo aqueles pertencer ao Estado costeiro. Portanto, a possibilidade de serem reivindicados por esse Estado permaneceria em aberto.

Pinto (2016), ao citar Trombetta-Panigadi (1996), lembra que alguns autores defendem a imunidade dos icebergs a todas as reivindicações de soberania, podendo ser tratados como recursos naturais apropriados por todos. Isso significa que, caso os icebergs estejam além da zona econômica exclusiva do Estado ribeirinho, devem ser tratados como recursos naturais passíveis de livre apropriação, não pertencendo mais ao Estado costeiro em cujas águas se originaram primitivamente.

Noutra corrente, há os que defendem que os icebergs têm origem no Continente Antártico, uma área internacionalizada, e que sua exploração geraria recursos vistos como Patrimônio Comum da Humanidade.

Portanto, a questão jurídica que dá relevo ao problema do aproveitamento das águas doces dos icebergs está longe de estar pacificada. Os critérios de localização e origem quando da possível exploração destes recursos contrapostos à noção de patrimônio coletivo - sejam eles minerais ou não - parecem representar outro ponto nevrálgico deste artigo.

$\mathrm{O}$ fato é que, devido à sua inegável importância no cenário global e à crescente escassez de água doce já contextualizada anteriormente, torna-se também imperioso vincular o debate a quatro princípios: o princípio da não apropriação e exclusão da soberania; o princípio do uso pacífico; o princípio da liberdade de acesso, exploração e pesquisa científica e, por fim, o princípio da gestão racional dos recursos e distribuição equitativa para o benefício da humanidade. Pinto, ao citar Joyce (1991), considera que: 
Las reclamaciones en la Antártica no son válidas ni reconocidas por el derecho internacional. Como el continente no tiene un legítimo dueño, por lo tanto, debería ser legalmente declarado como res communis, espacio común que pertenece a toda la humanidad. Los fragmentos de hielo derivados desde el espacio común de la Antártica deberían ser naturalmente considerados parte del patrimonio común de la humanidad, y los beneficios provenientes de los recursos de hielo distribuidos internacionalmente, con preferencia a los países menos desarrolhados (PINTO, 2016, p. 5).

Coloca-se grande carga de incerteza no fato de discussões sobre o tema "gelo" praticamente inexistirem nas Reuniões Consultivas do Tratado da Antártida. Tanto os aspectos técnicos quanto os aspectos legais relacionados aos icebergs deixaram de proporcionar amplo debate entre as parte consultivas.

Quanto ao fator ambiental, o Protocolo não se refere claramente à questão da exploração do gelo. $\mathrm{O}$ art. 3 (2), b (iii) afirma que as atividades na área do Tratado da Antártida devem ser planejadas e conduzidas de maneira a evitar mudanças significativas na atmosfera terrestre, aquática, glacial e marinha. Essa menção, embora isolada, visa deixar claro que o conjunto de princípios ambientais deve ser aplicado em uma eventual exploração do gelo (PINTO, 2016, p. 5).

Isso se ajusta à ideia trazida por Toledo sobre os reflexos que as atividades humanas têm sobre o ambiente:

Toda a atividade humana sobre o meio ambiente causa inevitavelmente repercussões reais. Essas alterações na organização natural dos ecossistemas podem ser significativas ou não significativas. O Direito Internacional procura fornecer instrumentos para impedir a ocorrência de eventuais repercussões prejudiciais significativas, na medida em que todo trabalho humano sobre as matérias-primas da natureza causam inevitavelmente um impacto sobre o meio ambiente (TOLEDO, 2016, p. 33).

A complexidade da questão deve sempre ser tratada sob a perspectiva do mandamento trazido pelo Artigo $7^{\circ}$ do Protocolo de Madrid, que estabelece a proibição de explorar recursos minerais no território Antártico.

Mais uma vez recorrendo à contextualização trazida por Pinto (2016), o autor assevera que, em havendo tecnologias viáveis no futuro, não se aplicaria nenhum impedimento à coleta no caso de exploração do gelo. Isto porque a XI Reunião Consultiva Especial do Tratado Antártico (RCETA) não considerou a exploração do gelo atividade minerária. Na mesma reunião ficou acordado que, se a exploração do gelo se tornasse possível, entender-se-ia que as disposições do Protocolo seriam aplicáveis, com exceção do Artigo $7^{\circ}$. 
Portanto, segundo o entendimento que prevalece na maioria dos países consultivos do Tratado da Antártida, o gelo, notadamente os icebergs, está excluído do impedimento legal previsto no artigo $7^{\circ}$ do Protocolo, reconhecendo-se a aplicação de todas as outras disposições a uma possível exploração deste recurso na área em que opera, isto é, ao sul de $60^{\circ}$ de latitude sul.

É certo que a natureza jurídica dos mantos de gelo da Antártida não foi submetida ao necessário debate por parte do Direito Internacional. Relacionando esta falha à questão da coleta dos icebergs, entendemos que as normas gerais do direito do mar não se mostram suficientes para resolver o imbróglio da exploração.

Finalmente, chega-se à ideia de que o mais sensato seria proceder à criação de um status jurídico especial para tratar desses recursos, definindo-se clara e objetivamente se são ou não recursos minerários.

Além do mais, assim como definido em várias convenções sobre a utilização de outros recursos naturais tais como a pesca do krill ${ }^{4}$ e a caça das baleias, a questão da exploração de icebergs no Território Antártico precisa de planejamento amplo para que sejam garantidas medidas ambientais protetivas aos vários ecossistemas complexos, interdependentes e que possam ser adversamente afetados pela exploração, transporte e beneficiamento da água.

\section{O TRANSPORTE DE ICEBERGS DA ANTÁRTIDA PELA AUTRÁLIA}

A porção sudoeste da Austrália é suscetível a secas devido à grave indisponibilidade de água doce, o que causa sérios problemas à população. A demanda por água doce nesse país é sempre crescente, sendo necessário que a oferta desse precioso bem acompanhe o ritmo.

É fato que as discussões sobre o reaproveitamento de água doce de icebergs do continente Antártico são antigas. A questão é tratada de forma minuciosa desde 1970. Inúmeros são os estudos de viabilidade que visam tratar das implicações econômicas, sociais e ambientais que esta possível solução traz em seu contexto fatídico.

O chamado Território Antártico Australiano (AAT) abriga 30\% dos icebergs existentes no mundo, sendo que toda a água resultante do seu derretimento e diluída na água

\footnotetext{
${ }^{4}$ Krill antártico (Euphausia superba) é uma espécie de krill que vive nas águas do Oceano Antártico. É uma espécie-chave no ecossistema antártico, sendo provavelmente, em termos de biomassa, a mais bem sucedida das espécies animais do planeta (500 milhões de toneladas) (Fonte: Wikipédia)
} 
do mar poderia contribuir sobremaneira para a solução do problema de água doce na Austrália caso fosse coletada.

Conforme já dito neste artigo, para que a água doce seja explorada e reaproveitada, as questões tecnológicas (especialmente o sistema de transporte), as considerações jurídicas e os impactos ambientais que irão recair sobre os ecossistemas marinhos precisam ser superados.

O sistema de transporte de icebergs na Austrália é proposto por SPANDONIDE, 2012 e se divide em três etapas principais:

1. belting and wrapping of the iceberg in-situ with a bag and a collar;

2. transportation of this system into warmer areas and the collection of the melted water of the iceberg in the collar and specific fresh waterbags, and

3. waterbag transportation from Antarctica to Australia using sustainable techniques of current drifting and kite towing. (SPANDONIDE, 2012, p. iv)

O fato é que a exploração dos icebergs do Continente Antártido pela Austrália ou por qualquer outro país interessado está sujeita a amplas discussões. Entretanto, os possíveis problemas ambientais e jurídicos relacionados à exploração dos icebergs são subestimados pelos acordos entabulados, não existindo nenhum status legal específico para a questão.

Recorre-se novamente às explicações trazidas por SPANDONIDE, 2012:

New demands and possibilities for iceberg transportation between Antarctica and Australia raise new legal issues. (SPANDONIDE, 2012, p.351)

Embora a Austrália possua inquestionável status de protagonista na Comissão para a Conservação dos Recursos Vivos Marinhos Antárticos, a legislação desse país ainda carece de amadurecimento no que concerne à questão enfrentada.

Nota-se ainda que a viabilidade da exploração dos icebergs pela Austrália perpassa por muitas questões conceituais que já foram abordadas no capítulo sobre a natureza jurídica desse recurso natural e também sobre o exercício da soberania do Estado ribeirinho de coletar as plataformas flutuantes de gelo livremente, adotando as medidas ambientais adequadas mediante criteriosos Estudos de Impacto Ambiental.

\section{CONSIDERAÇÕES FINAIS}

O problema da escassez de água no mundo todo despertou um novo olhar para a Antártida. A exploração e o uso da água doce obtida pela exploração dos icebergs deixam o 
campo das utopias e passam a representar uma solução atraente para que o déficit que aflige vários países seja resolvido.

Entretanto, muitos desafios ainda precisam ser enfrentados para que isso seja possível: o próprio fator locacional e o fato de a Antártida ser um continente inóspito, além das questões tecnológicas para as quais ainda não se tem uma solução viável que permita o transporte desses blocos de gelo por navios até os locais de consumo.

A partir do que foi exposto, vemos que a literatura especializada não traz com total clareza a classificação dos icebergs, se têm natureza jurídica de recurso mineral ou não. No presente artigo, buscou-se emprestado no campo da engenharia de minas e da geologia fundamentos para verificar essa distinção.

Pelos conceitos analisados ao longo do trabalho e pelas características delineadoras dos recursos minerais, entendemos que sim, os icebergs são recursos minerais visto que possuem aspectos físico-químicos, valor econômico e potencial para futura exploração.

Esta indefinição é fator de desconforto na legitimação de uma futura exploração do gelo devido ao impedimento do artigo $7^{\circ}$ do Protocolo de Madrid, que estabelece a proibição de explorar recursos minerais no território Antártico.

Acrescido a este imbróglio, também se conclui que a situação legal incidente nas questões da Antártida tem desdobramentos singulares e nada convencionais no cenário global, no campo do Direito Internacional.

O Sistema do Tratado da Antártida representa um emaranhado normativo complexo resultante de discussões entre vários países consultivos que dá contorno ao que é ou não permitido no continente austral e nas águas que o cercam até $60^{\circ}$ de latitude sul. Esse ordenamento, na forma em que se encontra atualmente, acaba por inviabilizar a aplicabilidade do Direito do Mar, carecendo de um tratamento personalíssimo quanto às questões da Antártida e, especialmente, à exploração dos icebergs.

É necessário que seja aplicado aos icebergs um status normativo próprio através de um novo marco regulatório relacionado aos assuntos que tangenciam a sua exploração.

Outra conclusão a que se chega é a necessidade da criação de um órgão gestor que possa dirimir todas as questões relativas à exploração dos icebergs da Antártida, inclusive com poderes para a mediação de interesses conflitantes entre países e relacionados a tal recurso, e, principalmente, sobre as questões ambientais, buscando alinhar a coleta desse importante recurso ao respeito e zelo máximos com o meio ambiente afetado. 


\section{REFERÊNCIAS}

AGUERO, Pedro Hubertus Vivas. Avaliação econômica dos recursos naturais. 1996, 170 f. Tese de Doutorado. Universidade de São Paulo, São Paulo, 1996.

BAPTISTA, Michelle Oliveira. O Sistema do Tratado da Antártica (STA): origem, desafios e impactos sobre a geopolítica do atlântico sul no Século XXI. 2015, 71f. Trabalho de Conclusão de Curso. Universidade Federal do Rio Grande do Sul, Porto Alegre, 2015.

BRUM, Antônio Coimbra de. Antártica: proteção no Direito Ambiental Internacional e participação brasileira. 2015, 80f. Monografia. Universidade Federal do Rio Grande do Sul, Porto Alegre, 2015.

BUCHHEISTER, Gustavo Ramírez. Wordie house: un caso de daño medioambiental en la antártica. Cuadernos de extensión jurídica, n. 28, 2016, p. 183-208. Disponível em: <https://www.researchgate.net/publication/315876516_Wordie_House_Un_caso_de_dano_m edioambiental_en_la_Antartica.>. Acesso em: 01/07/2018

COSTI, Juliana. Derretimento superficial e descarga de água de derretimento nos últimos 34 anos na Península Antártica. 2015, 114f. Tese de Doutorado. Universidade Federal do Rio Grande do Sul, Porto Alegre, 2015.

COUTINHO, Lilian. Água - Recurso Mineral: o paradoxo hídrico resultante da regulamentação jurídica aplicada às águas minerais no Brasil. Projeto final em Ciências Ambientais - Consórcio IG / IB / IQ / FACE-ECO / CDS. Universidade de Brasília. Brasília DF, 2015.

DECRETO No 2.742, DE 20 DE AGOSTO DE 1998. Promulga o Protocolo ao Tratado da Antártida sobre Proteção ao Meio Ambiente. Assinado em Madri, em 4 de outubro de 1991. Disponível em: <http://www2.camara.leg.br/legin/fed/decret/1998/decreto-2742-20agosto-1998-343204-publicacaooriginal-1-pe.html>. Acesso em: 05/07/2018.

FELICIO, Ricardo Augusto. Antártida A Geografia do Continente Gelado e as Operações Brasileiras. IV Semana de Geografia. A escola pública sob novos olhares e novas atitudes: cercas e pontes entre universidades e ensino de Geografia. Disponível em: 
<http://www.geografia.fflch.usp.br/graduacao/apoio/Apoio/Apoio_Conti/Antartida.PDF>. Acesso em: 01/07/2018

FERREIRA, Felipe Rodrigues Gomes. O sistema do tratado da Antártica: evolução do regime e seu impacto na política externa brasileira. Brasília: Fundação Alexandre de Gusmão, 2009. 248p.

GUIA CBRR PARA DECLARAÇÃO DE RESULTADOS DE EXPLORAÇÃO, RECURSOS E RESERVAS MINERAIS. Preparado pela Comissão Brasileira de Recursos e Reservas - CBRR. Edição 2016. Brasília, DF. Disponível em:

<http://www.cbrr.org.br/docs/guia_declaracao.pdf>. Acesso em: 05/07/2018.

LOOSE, Fabrício Ferreira. Bioprospecção na Antártida. 2011, 106f. Dissertação de Mestrado. Universidade Federal do Rio Grande do Sul, Porto Alegre, 2011.

MARINHA DO BRASIL. Tratado da Antártica e Protocolo de Madri. Comissão Interministerial para os Recursos do Mar. Secretaria da Comissão. $2^{a}$ edição. Brasília, DF: SECIRM, 2016. 72p.

MARQU. La condicion juridica del Artico y la Antartica: un asunto pendiente en la agenda juridico-politica de las relaciones internacionales contemporaneas. Relaciones

Internacionales, n. 107, maio de 2010. Disponível em:

$<$ https://doctrina.vlex.com.mx/vid/artico-antartica-internacionales-contemporaneas238386938>. Acesso em: 15/05/2018

PLANO NACIONAL DE RECURSOS HÍDRICOS. Síntese Executiva - português / Ministério do Meio Ambiente, Secretaria de Recursos Hídricos. - Brasília: MMA, 2006. 135p. Brasil. Disponível em:

<http://www.mi.gov.br/documents/10157/3675235/PLANO+NACIONAL+DE+RECURSOS +HIDRICOS.pdf>. Acesso em: 05/07/2018

PINTO, Francisco Lertora. Los icebergs en la Antártica. Revista Estudios Hemisfericos y polares. V. 7, n. 2, p. 1-19, Abril-Junio, 2016. Disponível em:

http://www.revistaestudioshemisfericosypolares.cl/articulos/102-Lertora- 
Revista_Estudios_Hemisfericos_y_Polares_Vol_7_N_2_(Abril-Junio_2016).pdf >. Acesso em: 02/07/2018

PRESS, Frank et al. Para Entender a Terra. Tradução: MENEGAT, R. (coord.). 4. ed., Porto Alegre: Bookman, 2006. 656 p.

ROCHA-CAMPOS, A. C.; SANTOS, Paulo Roberto dos. Ação geológica do gelo. In:

Decifrando a terra. 2000. Disponível em <https://pt.scribd.com/doc/33750456/Decifrando-aterra-cap-11-acao-geologica-do-gelo>. Acesso em: 01/06/2018

RODRIGUES, Fillipe. Proteção Ambiental das Áreas Globais Comuns. e-Pública: Revista Eletrónica de Direito Público, Lisboa, v.4, n.2, nov. 2017. Disponível em:

$<$ http://www.scielo.mec.pt/scielo.php?script=sci_arttext\&pid=S2183-184X2017000200008 . Acesso em: 07/06/2018

SANTOS, Leo Evandro Figueiredo dos. As alterações dos Anexos do Protocolo ao Tratado da Antártica sobre Proteção ao Meio Ambiente: a constitucionalidade independentemente da não submissão ao Congresso Nacional. 2017, 129f. Dissertação de Mestrado. Universidade de Caxias do Sul, Caxias do Sul, 2017.

SERRA, Silvia Helena. Águas minerais do Brasil. Campinas: Millennium, 2009. 277p.

SIMÕES, Carolina Lorenz. Retração das geleiras Drummond e Widdowson em respostas às recentes mudanças ambientais na península antártica (1957-2016). 2017, 80f.

Dissertação de Mestrado. Universidade Federal do Rio Grande do Sul, Porto Alegre, 2017.

SIMÕES, Stefany Lucchesi. A questão territorial Antártica: uma análise das teorias de ocupação. Revista de Iniciação Científica da FFC. v. 14, n. 1, 2014. Disponível em:

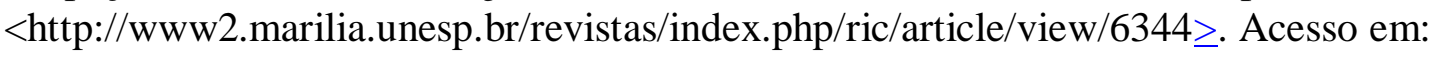
05/07/2018. 
SPANDONIDE, Bruno. Iceberg Water Transportation from Antarctica to Australia. 2012, 483f. Tese de Doutorado. School of Geography and Environmental Studies. University of Tasmania, 2012. Disponível em: <https://eprints.utas.edu.au/14798/2/whole-spandonidethesis.pdf $>$. Acesso em: 01/07/2018.

TEIXEIRA, Wilson et al. (Orgs.) Decifrando a Terra. São Paulo: Oficina de Textos, 2000. $568 \mathrm{p}$.

Teixeira, Silvana. Água - recurso natural de alto valor econômico, estratégico e social. Cursos CPT da área Meio Ambiente. s.d. Disponível em: <https://www.cpt.com.br/pararefletir/agua-recurso-natural-de-alto-valor-economico-estrategico-e-social>. Acesso em: 01/07/2018.

TOLEDO, André de Paiva. A proteção jurídica internacional da biodiversidade marinha. Revista Veredas do Direito, Belo Horizonte, v. 13, n. 27, p. 31-62, set./dez. 2016. Disponível em: <http://www.domhelder.edu.br/revista/index.php/veredas/article/view/924>. Acesso em: 01/07/2018.

TORRES, Claudia Sampedro. Uma esperanza a la deriva. Oásis, Red de Revistas Científicas de América Latina y el Caribe, España y Portugal, n. 13, 2008. Disponível em: <http://www.redalyc.org/html/531/53113141013/>. Acesso em: 16/06/2018.

UNITED STATES DEPARTMENT OF THE INTERIOR. Principles of the Mineral Resource Classification System of the U.S. Bureau of Mines and U.S. Geological Survey. 1976. Disponível em: <https://pubs.usgs.gov/bul/1450a/report.pdf>. Acesso em: 16/06/2018.

VICUÑA, Francisco Orrego. La definicion de un regimen para los recursos minerales antarticos: opciones básicas. Estudios Internacionales, s.d. Disponível em:

<https://revistaei.uchile.cl/index.php/REI/article/view/16128>. Acesso em: 16/06/2018.

VIEIRA, Friederick Brum. O Tratado da Antártica: Perspectivas Territorialista e Internacionalista. Cadernos PROLAM/USP, ano 5, v. 2, p. 49 - 82, 2006. Disponível em: $<$ https://www.revistas.usp.br/prolam/article/view/81808>. Acesso em: 02/07/2018. 
WEEKS W. F; CAMPBELL, W. J. Icebergs as a fresh-water source: an appraisal. Journal of Glaciology, v. 12, n. 65, 1973. Disponível em:

$<$ https://www.cambridge.org/core/services/aop-cambridge-

core/content/view/9A8294234261CD40EAA70502664ADBA7/S0022143000032044a.pdf/ice bergs_as_a_freshwater_source_an_appraisal.pdf>. Acesso em 01/06/2018.

\section{SITES CONSULTADOS}

Água - recurso natural de alto valor econômico, estratégico e social. Disponível em: https://www.cpt.com.br/para-refletir/agua-recurso-natural-de-alto-valor-economicoestrategico-e-social. Acesso em: 01/06/2018.

Can We Use Icebergs As A Source Of Water? Author: Ashish_Disponível em: $<$ http://sciabc.us/kX5Fz> Acesso em: 05/07/2018.

Classifying natural resources_Disponível em: <https://www.soas.ac.uk/cedepdemos/000_P505_NRE_K3736-Demo/unit1/page_08.htm> Acesso em: 02/07/2018

Discovering Antarctica_Disponível em: <https://discoveringantarctica.org.uk/> Acesso em: 02/07/2018

Marshall Brain "What if people wanted to use icebergs as a source of fresh water?" 18 February 2008. Disponível em:

<https://science.howstuffworks.com/environmental/earth/oceanography/icebergs-aswater.htm> Acesso em: 13/06/2018. 